\title{
International Librarianship and Its Impact on the Profession
}

\author{
by Diann Rusch-Foja
}

\begin{abstract}
This paper is adapted from a presentation at the SLAAnnual Conferences, SLA Education Division, June 11, 1996 in Boston. It focuses on time aspects of international librarianship and its impact on the profession: language and the national imbedment of certain information sources, especially that of the education field as part of the social sciences in general; cooperation (intemational, national, regional) for gathering and evaluating relevant Internet resources; and a demonstration of the German Educational Resources Server as an example of what could be done theoretically.
\end{abstract}

\section{Introduction}

How do we define "intemational" librarianship? What is "intemationalism?" What is "intemational librarianship?" Without taking Webster in hand, I would like to define "internationalism" as "the ability to identify or create a common understanding between different nationalities and different cultures." This involves both recognition of the cultural similarities, but more importantly the differences and distinctions. Within the "leveling" effect of becoming "international" assimilating in several cultures - there is a precedence to maintain respect and separatedness for the individuality of the individual nations and peoples. Taking the word literally in its etymological stem, we mean we are being between nations, joining the common parts, but recognizing the non-overlapping aspects as being larger and just as important, as well as understanding them.

So what is "intemational librarianship?" It is not enough to understand the language, or see the similarities or differences between various countries, nations or populations. It is defining and moving in those professional realms where common ground and interests form essential, universal goals shared by all within the periphery of distinctly individual social customs, laws, educational and work systems, mentalities, economic standards, etc. In librarianship, these essential, universal goals are easy to list and define. Usually the introductory library school courses deal with them, although perhaps their impact is not revealed until one truly deals with internationalism in librarianship. These include preserving the freedom of expression, the freedom of access to information, the right - not the privilege - of leaming to read, and the right to protection from discrimination, injustice, persecution, etc., for actively protecting these other rights and freedoms. These can be applied to the local, national and international level: on the intemational level, the UAP (Universal Availability of Publications) Program and other IFLA Core Program activities help to fulfil these goals.

\section{Impact on the Profession}

Intemationalism has great impact on the profession. The creation of the IFLA (Intemational Federation of Library Associations) is an indication of this impact and the profession's attempt to bridge international gaps and successfully plan and carry out international projects and programs to further the supranational goals, those going beyond the power and jurisdiction of the individual countries. Librarians' exchanges, such as the ALA Fellows program, create the chance to share professional experiences intensively, especially in countries where inter-national-ism was carefully defined and confined to interaction between countries with similar political structures. Student exchanges offer great opportunities for leaming about the internal structures of libraries and librarianship, as do consulting work by professionals, international training seminars and workshops, etc. So for our profession, internationalism is not only based on common, universal goals, or understanding differences, but also being able to apply methods from one culture in another effectively or to use exchange and input from several to create new methods of solving problems and maintaining the above goals. 
This paper will touch on three aspects of international librarianship and its impact on the profession. These are:

1. language and the national imbedment of certain information sources, especially that of the educational field as part of the social sciences in general,

2. cooperation (international, national, regional) for gathering and evaluating relevant Internet resources, i.e. the aspect of internationality which Internet has brought to all areas, but especially to information provision professions, and

3. a demonstration of the German Educational Resources Server as an example of what could theoretically be done, including the experience drawn upon for international cooperation among educational libraries. It is hoped that the experiences related here could encourage or maybe even inspire more efforts at international cooperation in librarianship to make a positive impact on the profession.

\section{1. Language and the National Imbedment of Certain} Information Sources, especially in the field of Education

Language is a product of cultural, sociologically imbedment phenomena. Language skills show direct correlations to cognitive skills and development. There is also research which indicates that a national language itself is a product of certain aspects of a "national" mentality, religion or philosophy. Some people even believe linguistic characteristics of a language could be related to geographical phenomena, etc. This may be taking the hypothesis too far, but I do believe there are definite relationships between a language, its structure, its composition of words, and its environment, i.e., the social structure of the country, the mythology or "collective unconscious" of a people. This also poses the chicken and the egg question: is language a process of thought, does cognitive mapping of the environment also prescribe how linguistic structures are built? Similar questions could continue, but must be dealt with by more competent anthropological linguists and perhaps even then, there is no definitive answer.

However, the results of divergent linguistic structures (ways of describing things, ways of categorizing and thinking about things), as well as the structures themselves belong to national qualities which provide distinction. Translation from one language does not always establish the common ground to talk about the subject at hand. Incompatibilities arise when directly comparing or even verbally describing social systems of various countries. ${ }^{1}$ The problems begin at the linguistic level of verbal descriptors. This can extend from difficulties in the translation or description of the terms and their meaning. For example, compare the meanings of the German words "Kindergarten" and "Vorschule" to the American equivalents "kindergarten" and "pre-school." Even many people who understand German and English are tempted to see the similarities of these words and translate them accordingly. However, one must be acquainted with the educational and social structures in which these words are imbedded. The German "Kindergarten" can only be translated into English as "pre-school" or "nursery school" and the German "Vorschule" is actually the equivalent of the level of the American "Kindergarten." (Did Carl Schurz and his wife reckon with this one hundred and forty years ago when in 1856 Mrs. Schurz started the first Kindergarten in Watertown Wisconsin and shortly thereafter her husband pleaded in Congress for German and the national language?)

But the incompatibilities of language, understanding, and socially imbedded structures do not end there. Because the structure and content of many of the social sciences are closely interrelated with the social systems of the individual country (educational system, societal practices, parliamentary and legal system, social services structures and other contextual aspects of human life), the organization and representation of the content often remains very individual, distinctly non-international and sometimes even contradictory. Consequently, the ways of describing their information collections also hide certain incompatibilities. Some international similarities can be distinguished - some can also in part be attributed to the impact of new technology in both the field itself and in information work, especially the work of attempting to define internationally valid descriptors and equally valid classification systems. But if one talked about key issues in the German educational system, forinstance, the "Zweiter Bildungsweg" or the "Duales System," and translated them as "second way to education" and "dual system," nobody would have any idea of what was meant? Can these concepts be related to practices in other countries? And even if not, is there an indication of what is meant by these terms?

These examples show that the sociological structures of a country determine how we talk and conceptualize about them. Thus, the high proportion of both content and linguistic individuality of a nation remains to challenge librarians who want to step beyond the home language bounds towards internationality.

The increased use of the Internet presents an analogous situation and thus creates subject-oriented challenges to the librarian. This affects not only the methods and instruments used for information retrieval and acquisition, but also the development of value-added services which can place appropriate information in the correct context and also provide targeted information in a vastly expanding field. To be more concrete, a German descriptor might not get many hits from a query using a particular search engine. This may indicate a lack of materials on the Internet in the German language which is still a definite fact. But, even using a translation into English combined with "German" or "Germany", the results, when looked at more closely, may also indicate that the translation for this word or concept is focused on the basis of a structure in one linguistic world which, however, does not exist in the language used for the search or in the selection of documents used as the basis for the particular search engine. This is a phenomenon which holds true for many non-English sources, not just pertaining to those in the German language. Whether this means 
that non-English producers of Internet documents should create them in English or at least create parallel editions to the native language documents is a question which may have to be decided on individually. Many disciplines have already agreed upon English as the language of scientific communication, but others - especially in the social sciences - have not.

Also the matter of language - or more precisely not using the native language - is often a very political matter in a country, and is looked at differently in various countries. Some smaller countries use English extensively, even for entire university or technical college courses to prepare their graduates for international work. Here the libraries function totally in English and their collection has about $90 \%$ English language texts. In other countries, there is a latent fear that if the native language is not used in key situations, it will be lost or die out, or the country will not remain authoritative in the particular scientific community. So there is a very strong emphasis on publishing in both the native language and in English. One solution to this problem would be the creation of metadata for Internet sources in English for foreign language documents which would at least enable searching. ${ }^{2}$ This creates content accessibility, but still does not overcome the language problem per se. Furthermore, English equivalents of foreign concepts for metadata may not completely correspond to the concepts or structures being described the translation is either "empty" of meaning, or even more critical, the English concept may be used as the translation or equivalent for concepts in various countries which do not correspond to each other at all.

In the field of education, increased use of the English language as a communications means among educational researchers, especially as a publication language, a conference language, and the language of resources in the Internet may relieve some of the incompatibilities of meaning between the translation and the original concept. But, as mentioned above, translations may not always be completely accurate because of the limitations of the English language or the limitations of comparing two completely different sociopolitical structures.

There is an internationalizing effect of working with the Intermet. For foreign librarians with international clientele and for their own attempts to keep up with the developments in other outstanding countries, the Internet offers a variety of means to improve communication, create access to new sources and strengthen the foreigners' knowledge of the English language. For instance, being a participant in several international discussion lists, can serve as a "current awareness" alert to new developments, identify people with similar problems or interests, and easily create contacts. It can also be used as a sort of continuing education substitute for increasing familiarity with the English terms for a foreign staff. Especially in international institutions with a high ratio of foreign guest researchers, postdocs and doctoral candidates where English becomes the lingua franca, each member of the foreign library staff must be able to speak, understand and work in the English language. For instance, in our Institute library, we currently have nine nonGerman language researchers, four native English language secretaries of the directors, and one native English speaker as editor of the Berlin Aging Study publications. So a flair of internationality prevails in the Institute, which is evident in many of the 66 Max Planck Institutes and approximately 30 Research Groups affiliated with and temporarily financed by the Max Planck Society. The library provides monthly library tours and ad-hoc introductions for Institute staff in German, English and French. Many of the staff are fluent in English and can answer reference questions in English. This means the librarianship is practiced in a basically international background. Similar aspects of internationality can be found in many research institutions all over the world, as well as in institutions with large international markets, political and social influence, etc.

However, the real aspects of international librarianship arise through contact with librarians in similar special libraries in other countries. This is especially true for the one-person-libraries in very specialized institutions. Here, despite the isolation of these "solo librarians" in their own country, the contact facet of international librarianship can play an important role in supporting the daily work of the one-person-library.

2. cooperation (international, national, regional) for gathering and evaluating networked (Internet) resources, i.e. the aspect of internationality which Internet has brought to all areas, but especially to information provision professions

The basic role of international librarianship is hamessing multinational efforts for cooperative projects which could not otherwise be carried out. The IFLA is a prime example for this, as is the Conference of National Librarians. International cooperation will be more library type or subject oriented. Important aspects are concerned with information access and provision beyond the international borders and the restrictions of languages. Cooperative agreements are well known in these areas (exchange agreements for of ficial and government publications, international interlibrary lending, etc.). ${ }^{3}$

Similar to the traditional fields of international cooperation, now the massive opening of access to even more information resources in the Internet creates an even greater need for cooperation among librarians and information specialists than ever before. Subject specialists even in a single country cannot keep up with finding, evaluating and classifying Internet resources in their field. Ideally, this could be achieved more satisfactorily if the concept of "distributed information systems" which is the basis for World Wide Web clearinghouses, virtual libraries, subject gateways, subject trees, and other similar collective information resources sites, could be coordinated internationally. This may be analogous to the many attempts at international databases and bibliographies for certain subject fields in the past. However, the Internet offers extended access to information in the Internet to virtually anyone, unrestricted publication possibilities (i.e., not having to be published in an indexed journal), and currency which contribute to making such an undertaking as "indexing the Web" paramount to a Sisyphus task impossible to be achieved by a single person, group or company. This was evident again to me when looking at what Deborah S. Garson has accomplished with her Web site at the 
Harvard Gutman Library site and what we have experienced in setting up our Web site. ${ }^{4}$ Especially during the efforts to set up a Clearinghouse for Project-oriented Networked Information, we have searched the Internet, collected and evaluated sites for their informational value for the researchers in the Institute and structured them into several web pages - resource pages for general or more project-specific pages. (Examples of the Clearinghouse entry page and a Resource Page for Educational Resources (General) are included here as Figures 1 and 2). The Institute also has about 6 major cross-national research projects, for instance the Third International Mathematics and Science Study which focuses on empirical data from classroom observation of mathematics and science teaching in the U.S., Germany and Japan (see Figure 3). The Institute is also involved in multinational studies for the study of teaching ethics in school, as well as several projects on changes in schools, social structures and work situations in the former Socialist countries in comparison with Western countries. One of the psychology department's studies looks at empirical data on children's scholastic achievement in relationship to their self-appraisal and control beliefs in Los Angeles, Tokyo, Moscow, and Berlin. These projects require collecting a great deal of background information for these researchers, some of which have been collected using the Internet. In addition, these areas will continued to be maintained in a Web site at our Institute with a link from the Internet coordinator at the major psychological special subject library in Germany, the Center for Psychological Information and Documentation in Trier. Similarly, resource pages referring to subject information in the Internet pertinent to some of our sociological research projects will be linked from the Information Center for the Social Sciences in Bonn in coordination with their efforts so that a minimum of duplicated effort occurs.

Certain national efforts to organize subject-oriented collection and indexing of Internet resources exist in Germany. More encompassing national programs are underway in Great Britain (BUBL 5 , NISS, ROADS6, OMNI7 ${ }^{7}$, SOSIG ${ }^{8}$ etc.) and Australia (ANU WWW Virtual Library Information Servers9). It would be a worthwhile contribution to international librarianship if librarians in other countries could be instrumental in achieving similar structures.

Another example of intemational cooperation which will increase in importance in the future is the exchange of ideas and opinions on information quality concerning resources on the Internet. Since April of this year, an e-mail discussion group on information quality has been created and the interaction on this list has been very active. A Web site on Information Quality has been created by the list moderator T. Matthew Ciolek ${ }^{10}$ (in Australia). This includes a section in which he collected various criteria for defining information quality on the Internet. Other participants contributed greatly, so that already this Web site is a rich source of thought, literature, and preliminary standards (for instance citation standards for citing networked information) on this topic. This is a prime example of cooperative efforts which achieve the goals of international librarianship.
3. The German Educational Resources Server, an example of how national cooperation can flourish and where international cooperation among educational libraries could contribute even more to making a positive impact on the profession.

In Germany, a Web-site is just being created for German Educational Resources ${ }^{11}$ on the basis of cooperation between the 16 German states or Länder, various professional societies for educationalists and education researchers, subject librarians responsible for collections focusing on various aspects of education, schools and teacher training institutions, teachers, and even subgroups of other professional societies involved with the didactics of teaching their particular subject area. They are submitting materials to the Deutscher Bildungs-Server/German Educational Resources Server which is being coordinated by Professor Peter Diepold at the Humboldt University in Berlin with initial support by the German Research Network (Deutsches Forschungsnetz) and financed by the German Federal Ministry of Education and Research (BMBF). The English language home page of this server is included here as Figure 4; Figure 5 shows the menu page for one of the four sections, "Resources." In addition, Professor Diepold has developed a set of metadata indicators which will be filled in by the person submitting a HTML document to be linked to from this server. Thus, the person who is familiar with the content of the document will also index it. It is hoped that this practice will increase accuracy of the indexing terms. This will also bring more specific hits when searched by search engines. It should also reduce time delays in including links to documents which would be caused by submitting documents to editorial boards for indexing and cataloging. English-language terms will also be assigned by researchers who are familiar with the difficulties in translating German and English educational terms and relating the various German educational and vocational systems to those in other national structures. As part of the team which has conceived this site, we are looking forward to comments and to further expanding this site with links to other national educational Web sites.

Despite the difficulties in translating and transforming nationally imbedded concepts and structures in the educational field, similar efforts at the international level could produce very important contributions to understanding different educational structures and supporting information access. Surely similar efforts can be seen in the Web site of the National Library of Education. Theoretically, these experiences could be drawn upon for international cooperation among educational libraries, including both more exchange on their activities and perhaps informal coordination of cooperative efforts. The reduction of complexity of communications means and of the spatial restrictions of the past could result in more efforts at international cooperation in the field.

In the Anglophile countries (the U.S., Great Britain, Australia), special libraries have a more solid, higher standing than in many non-English speaking countries. This is due to the 
fact that English serves as the international language of librarianship, thus making it possible to expand these prime examples of international cooperation, particularly for the libraries in the SLA Education Division. More international contact, cooperation and joint results would certainly have a very positive impact on the profession, especially in those countries which are looking at the United States, Great Britainand Australia for leadership.

1 See Peter Wagner, Björn Wittrock (1991): States, Institutions, and Discourses: A comparative Perspective on the Structuration of the Social Sciences. In: Discourses on Society, The Shaping of the Social Science Disciplines. Vol. XV. Eds. Peter Wagner, Björm Wittrock, Richard Whitley. Dordrecht etc.: Kluwer, 1991, pp.331-357

2 This is often done in Scandinavian countries.

3 These are delineated in Anne Galler's paper from this same session.

4 The Web site for the Max Planck Institute for Human Development and Education is currently being set up, but should be available under the following address by the end of August 1996: http://www.mpib-berlin.mpg.de/
<http://www.bubl.bath.ac.uk/BUBL/>

$<$ http://www.ukoln.bath.ac.uk/roads/>

$<$ http://www.omni.ac.uk/>

$<$ http://www.sosig.ac.uk/>

$<$ http://www.anu.edu.au/>

<http://coombs.anu.edu.au/WWWVL-InfoQuality.html>

[13 May 1996]

$11<$ http://www.schule.de/> (Click on the underlined title "German Educational Resources" to obtain the English-language pages of this site.) A description of the server concept and database can be found at <http://www.schule.de/dbse.html>

Diann Rusch-Feja is the Director of Library and Research Documentation at the Max Planch Institute for Human Development and Education. Berlin, Germany. Prior to this, she has taught at universities and colleges in the United States and Germany and is also a specialist in Computer Systems for Information Systems.

email: ruschfeja@mpib-berlin.mpg.de 